\title{
Juegos de chicos, problemas de grandes
}

María Lucía Puppo'

UCA, CONICET

\section{Reseña de libro}

Punte, M. J. (2018). Topografías del estallido. Figuras de infancia en la literatura argentina. Buenos Aires: Corregidor. ISBN: 9789500531634, 352 pp.

Material original autorizado para su primera publicación en el Journal de Ciencias Sociales, Revista Académica de la Facultad de Ciencias Sociales de la Universidad de Palermo.

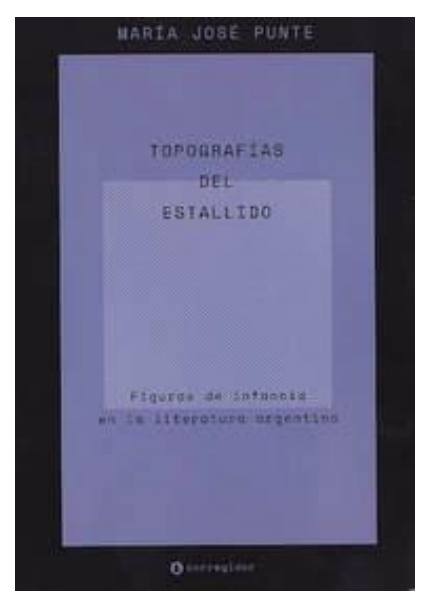

Resumen: El libro Topografías del estallido. Figuras de la infancia en la literatura argentina, de María José Punte, ofrece los resultados de un proyecto de investigación ambicioso en su alcance, como lo prueba el corpus seleccionado, que integra además un vasto marco teórico y metodológico. La hipótesis que atraviesa el estudio remite a la aseveración de Jacques Rancière que indica que la ficción es capaz de atestiguar "lo real de nuestro siglo en su dureza más radical" porque trabaja, justamente, sobre lo significante de lo insignificante. La consideración de la infancia nos invita a repensar las condiciones de "habitabilidad" -el término es de Judith Butler- a fin de idear nuevas y mejores formas de convivencia para niños y adultos.

\section{Introducción}

Un film entrañable de René Clément estrenado en 1952, Jeux interdits (Juegos prohibidos), narraba las andanzas de los pequeños Paulette y Michel mientras intentaban dar sepultura a los animales muertos que encontraban en los jardines de las casas. De ese modo,

\footnotetext{
1 Dra. en Letras. Directora del Centro de Estudios de Literatura Comparada "María Teresa Maiorana", Universidad Católica Argentina. Investigadora del CONICET. Correo electrónico: mlpuppo@uca.edu.ar
} 
a través de la mirada de una niña de cinco años y un niño de diez, el cineasta ofrecía una perspectiva nueva de la Francia ocupada durante la Segunda Guerra Mundial. El impacto que causó esta película se debía, probablemente, al estupor que provocaba la asociación de la infancia a la guerra. Atravesando las fronteras del tiempo y el espacio, la temática y el punto de vista asumidos por la película de Clément resultan muy cercanos a los treinta y cinco textos, entre novelas y colecciones de cuentos, que María José Punte aborda en Topografías del estallido. Figuras de infancia en la literatura argentina.

\section{Comentarios}

El libro ofrece los resultados de un proyecto de investigación ambicioso, como lo prueba el corpus seleccionado, que integra además un vasto marco teórico y metodológico. La hipótesis que atraviesa el estudio remite a la aseveración de Jacques Rancière que indica que la ficción es capaz de atestiguar "lo real de nuestro siglo en su dureza más radical" porque trabaja, justamente, sobre lo significante de lo insignificante (2013, p. 52).

En la Introducción se adelantan conceptos y debates claves que se irán desgranando en cada capítulo del volumen. Se plantea la necesidad de abordar la infancia más allá de su evidencia biológica, en tanto producto de tecnologías sociales derivadas de instituciones, discursos culturales y prácticas de la vida cotidiana. En su trayecto hermenéutico la autora reflexiona con el pensamiento filosófico de Giorgio Agamben (2007), quien asocia la falta de lenguaje de la infancia con lo inefable que caracteriza toda experiencia (p. 18), vinculada con el misterio y la mística, en oposición al lenguaje articulado del logos (p. 19).

La escritura caleidoscópica de Punte articula los juicios críticos y su apuesta se orienta a poner en cuestión y deconstruir los lugares comunes de la infancia, tradicionalmente asociados a una visión nostálgica idealizada, o bien al exitoso pasaje a la juventud que vehiculizaba el Bildungsroman clásico. En los relatos de la Argentina de fin del siglo XX y comienzos del XXI, en cambio, el niño suele asumir la figura de testigo de los hechos en su carácter de resistente o sobreviviente. Entretanto, la concepción de Freud del niño como un perverso polimorfo parece haber dado paso a la aparición del niño queer, tal como lo teoriza Kathryn Stockton (2004).

El Capítulo 1 lleva el sugestivo título de "La pérdida del rincón". La autora resume así el cambio de paradigma que se evidencia en nuestra literatura, donde el centro indiscutido ya no es la casa familiar. Lejos ya de las mansiones burguesas de antaño, Punte advierte la proliferación de distintas "topografías del estallido" en la literatura argentina contemporánea. La explosión de la familia nuclear genera en las ficciones formas de convivencia impensadas y nuevos cruces de lo social en torno a las variables de edad, clase y género. A la luz de la 
oralidad y el gusto camp cultivados por Manuel Puig, Punte analiza La maldición de Jacinta Pichimahuida (2007), novela de Lucía Puenzo que gira en torno a los avatares de un niño actor convertido en mercancía y fagocitado por la industria.

El Capítulo 2 explora una serie de textos que abordan la violencia de la historia a través de la mirada infantil. La lectura contrastiva de La casa de los conejos (2008) de Laura Alcoba, La casa operativa (2007) de Cristina Feijóo y Kamchatka (2003) de Marcelo Figueras pone en el centro el sufrimiento de los niños que han quedado atrapados en la coyuntura de los años setenta. Los secretos familiares son el eje en torno al cual se articulan El mar y la serpiente (2005) de Paula Bombara y El espíritu de mis padres sigue subiendo en la lluvia (2012) de Patricio Pron. En estas novelas Punte advierte un ejercicio de memoria que cuestiona las narrativas institucionalizadas, a través del acceso a lo que Leonor Arfuch denomina el "plano secreto" de la subjetividad, la zona donde habitan los miedos, las pasiones, las obsesiones y las fantasías (Arfuch, 2010, p. 174). Frente a este panorama tan complejo, la infancia surge muchas veces como mascarada o simulacro, condición actuada, performance: es el caso de Pequeños combatientes (2013) de Raquel Robles y El Dock (1993) de Matilde Sánchez. En esta última novela asistimos al nacimiento precario de una maternidad no biológica ni buscada. Como sintetiza Punte, el texto de Sánchez ejemplifica "la puesta en escena de este proceso por el cual dos sujetos, puestos juntos como víctimas de meras circunstancias externas, pueden abandonarse al proceso de entablar un vínculo que termina siendo familiar" (p. 133).

El Capítulo 3 indaga en varias narraciones que proponen una reelaboración de los cuentos tradicionales. Así, el bosque se asimila al tropo del laberinto en la versión macabra de Caperucita que constituye Wakolda (2011), de Lucía Puenzo. Por otra parte, la niña que protagoniza La batalla del calentamiento (2006) de Figueras convoca la figura del hada en tanto puente con lo maravilloso y lo extraordinario. Otras dos novelas trabajan la infancia a partir de la evocación de la escena de lectura: Yo era una niña de siete años (2005) de César Aira y Osos (2010) de Diego Vecchio. Como bien señala Seth Lerer, la historia de la literatura infantil ha sido también una historia de la imagen y del libro como artefacto (2008, p. 321). Siguiendo esta idea, Punte asocia el procedimiento de los textos de Aira y Vecchio con el despliegue de los libros troquelados, que cautivaban al niño -y luego al adulto- Walter Benjamin. En otras novelas, la representación de los niños se acerca a la del animal y el monstruo; es esa otredad la que resulta ominosa y amenazante en El niño perro (1993) de Miguel Vitagliano y El niño pez (2004) de Puenzo.

La problematización de la imagen generalizada de inocencia infantil llega a su punto máximo en el Capítulo 4, dedicado a las figuras del niño y la niña queer. La sexualidad perturbadora de los hijos logra desestabilizar las certezas adultas en Juegos de playa (2008) 
de Betina González y Los años que vive un gato (2011) de Violeta Gorodischer. Una sexualidad disidente con el orden heteronormativo se presenta en El Molino (2007) de Mariana Docampo y 9 Minutos (2005) de Puenzo. Cuando los roles de los padres han sido desplazados por la desidia o la violencia, los "chicos malos" cobran protagonismo para demostrar que no son más que seres profundamente heridos. Desde esta perspectiva se confrontan Las poseídas (2013) de Betina González y Rumble (2011) de Maitena Burundarena.

El Capítulo 5 examina la vinculación entre infancia y memoria a partir de la metáfora del álbum familiar. Apelando al dinamismo del dominó, la discontinuidad de las figuritas con brillantina, el caos de la sopa de letras y las palabras cruzadas, las novelas analizadas acuden al registro visual como puesta en abismo de su propia factura. A través de las fotografías, la familia escribe su historia y se produce a sí misma en un texto clásico como lo es Cuadernos de infancia (1937) de Norah Lange, y también en las versiones más cercanas que brindan Varia imaginación (2003) de Sylvia Molloy, Provincia de Buenos Aires (2005) de Laura Palacios, Alma inquieta (2011) de Graciela Schvartz y Una vez Argentina (2003) de Andrés Neuman.

La metáfora del diorama, aquel dispositivo óptico del siglo XIX, reúne a una constelación de novelas examinadas en el Capítulo 6. El prisma de la miniatura favorece la inserción de los niños y las niñas en el espacio nacional, es decir, la proyección de sus pequeños cuerpos en la arena pública donde se desenvuelve la Historia con mayúsculas. El desierto tendrá un rol central en El país del diablo (2015) de Perla Suez, mientras que en torno a la noción de intimidad se contará la Historia del llanto (2007) de Alan Pauls. En estas tramas se pone en duda, nuevamente, el resguardo que ofrece el hogar familiar: un caso extremo, en esta dirección, es el de la novela de Luis Mey, En verdad quiero verte, pero llevará mucho tiempo (2013).

La última sección del libro esboza las conclusiones del derrotero crítico. Se intitula "Tareas para el hogar", y detrás de este gesto cómplice hacia el mundo infantil se vislumbra la opción autoral de no clausurar el texto sino, por el contrario, de dejarlo abierto a la discusión y la reflexión ulterior por parte de los/as lectores/as. Es preciso destacar que el trabajo cumple con el objetivo de restituirles a las y los niños el lugar que ocupan en la literatura y la historia nacional. No se trata, desde luego, de un lugar fijo o unívoco, sino de una serie de derivas mediante las cuales las imágenes de infancia se revelan iridiscentes, ubicuas y cambiantes como un espejo (p. 33). La infancia se manifiesta como la materialización de una experiencia en busca de su propia voz, como la concreción de un auténtico experimentum linguae. Por otro lado, el mundo de los infantes parece continuar encarnando lo que Lyotard denomina la "comarca del deseo", el reino del como si ligado al poder de la imaginación, donde todo es 
posible. En las distintas encrucijadas diegéticas, los niños que presenta la literatura se revelan como víctimas y testigos involuntarios, unidos por la idea de haber llegado demasiado pronto.

\section{Conclusiones}

El libro de María José Punte pone bajo la lupa el trabajo incesante de la memoria, que convierte a la infancia en un proceso vital no necesariamente concluido en la etapa adulta ( $p$. 323). La infancia nos devuelve, en última instancia, lo reprimido que emerge de las sombras bajo el ropaje de una libertad explosiva. Si la vida es cambio, riesgo, un pasaje entre estados transitorios, la consideración de la infancia nos invita a repensar las condiciones de "habitabilidad" -el término es de Judith Butler- a fin de idear nuevas y mejores formas de convivencia para niños y adultos.

\section{Bibliografía citada}

Agamben, Giorgio (2007). Infancia e historia. Destrucción de la experiencia y origen de la historia. Trad. Silvio Mattoni. Buenos Aires: Adriana Hidalgo.

Arfuch, Leonor (2010). El espacio biográfico. Buenos Aires: Fondo de Cultura Económica.

Rancière, Jacques (2013). Figuras de la historia. Trad. Cecilia González. Buenos Aires: Eterna Cadencia.

Stockton, Kathryn B. (2009). The Queer Child. Or Growing Sideways in the Twentieth Century. Durham y Londres: Duke University Press. 